\title{
SIMULATION-DRIVEN DEVELOPMENT FOR COARSE COMMINUTION PROCESS - A CASE STUDY OF GEITA GOLD MINE, TANZANIA USING PLANTSMITH PROCESS SIMULATOR
}

\author{
Bhadani, Kanishk (1); \\ Asbjörnsson, Gauti (1); \\ Bepswa, Paul (2); \\ Mainza, Aubrey (2); \\ Andrew, Elibariki (3); \\ Philipo, Jisenha (3); \\ Zulu, Nkanyiso (3); \\ Anyimadu, Anthony (4); \\ Hulthén, Erik (1); \\ Evertsson, Magnus (1) \\ 1: Chalmers University of Technology, Sweden; \\ 2: The University of Cape Town, The Republic of South Africa; \\ 3: Geita Gold Mine, Tanzania; \\ 4: Anglo Gold Ashanti, The Republic of South Africa
}

\begin{abstract}
A comminution process is a material size reduction and separation process which is primarily used in the aggregates and the minerals processing industry. Knowledge related to equipment's operation, raw material properties, operational strategies, control system, maintenance, etc. is needed to design a capable plant. New needs are arising from the industry for existing operational crushing plants such as investigation for improvements, upscaling, and downscaling of the capacity. The paper presents an application of simulation-driven development for a crushing plant in an existing gold processing plant. Due to the change in ore characteristics and the need for optimizing the cost of operation, it is required to investigate the opportunities for improvement and alternative options for downscaling the capacity of the plant. A systematic process for configuring, developing, and evaluating alternative concepts using a process simulation tool is presented. The results show the process of generating knowledge for alternative crushing plant operation settings and how the choices can be selected and eliminated using boundary conditions. The evaluation presents possible improvements and alternative concepts with their opportunities and pitfalls.
\end{abstract}

Keywords: Gold-Processing, Decision making, Process modelling, Comminution, Case study

\section{Contact:}

Bhadani, Kanishk

Chalmers University of Technology

Department of Industrial and Materials Science

Sweden

kanishk@chalmers.se

Cite this article: Bhadani, K., Asbjörnsson, G., Bepswa, P., Mainza, A., Andrew, E., Philipo, J., Zulu, N., Anyimadu, A., Hulthén, E., Evertsson, M. (2021) 'Simulation-Driven Development for Coarse Comminution Process - A Case Study of Geita Gold Mine, Tanzania Using Plantsmith Process Simulator', in Proceedings of the International Conference on Engineering Design (ICED21), Gothenburg, Sweden, 16-20 August 2021. DOI:10.1017/pds.2021.529 


\section{INTRODUCTION}

A crushing plant typically consists of a series of equipment to reduce the material size from coarser size to finer size, typically, in range of $0-1000 \mathrm{~mm}$ to $0-30 \mathrm{~mm}$ depending on the operational requirements. The main equipment includes crushers (material size reduction), screens (material size separation), conveyors (material transport), feeders (material feed), bins (material storage), and splitters (material stream splitting), etc. To reduce the material to the desired size requirements, the circuit is generally built using multiple crushing stages (primary crushing, secondary crushing, tertiary crushing, etc.) with a certain capacity of mass flow and product size distribution. The design of the equipment, their sizing and configuration, the design of the plant layout, and the control system will determine the performance of the circuit. The crushing plant is used for both the aggregate industry and the minerals processing industry. In case of mineral processing industry, the coarse comminution circuit (crushing plant) is followed by fine comminution circuit (milling circuit) to further bring the product size to microns level for metal extraction in chemical processes. The size to which the ore is reduced depends on the requirements of the subsequent mineral extraction processes and the grain size of the valuable mineral (Wills and Napier-Munn 2006).

Steady-state modelling and simulation tools are widely used in designing of a new process for industrial coarse comminution circuit (crushing plant) (Napier-Munn et al. 1996; King 2001). There are multiple mathematical models for equipment, for example, the crusher mechanistic model (Evertsson 2000), crusher empirical model (Whiten 1972), screen model (Karra 1979; Soldinger 2002), bin and transport (Asbjörnsson 2015), etc. The simulation tools are powerful for designing new process plants, but it can be used for evaluating and upgrading existing circuits as well. The new investigation demands are typically for upscaling, downscaling or improvements in capacity and performance an existing crushing plant. Also, there are limited case studies present to show a systematic use of the simulation tool for industrial-scale application where the impact is higher. An appropriate methodological process is needed for such investigations using simulation tools. Typically, engineering design changes on the existing circuit need a full proof technological and economic feasibility which require wider expertise in the investigation.

The research paper presents a systematic approach applied for simulation configuration and calibration followed by concept generation for a full-scale industrial plant. The crushing plant used in the case study is a three-stage coarse comminution processing plant for gold production (Anglo Gold Ashanti, Geita Gold Mine, Tanzania). The simulation and evaluation of the problem are carried out using a newly developed cloud-based and steady-state simulation software, Plantsmith (Roctim AB, 2021). The investigation process together with the findings from the case study is presented.

\section{MODELLING AND SIMULATION PLATFORM}

The estimated transformation of the material from blasted ore to a finished product is simulated with a steady-state simulation platform Plantsmith in this study. The models are calibrated on an individual level for local validity. Then the overall simulation results are compared on a process level to evaluate the overall validity of the simulated results. The models and the platform are steady-state, and as the name implies, it simulates the process until an equilibrium for mass and energy has been achieved. In operational reality, the process is never in a complete equilibrium due to factors such as component wear, failures, control strategies, delays, un-match unit capacities, limiting throughputs, material variations and operators' decisions (Asbjörnsson 2015). Steady-state simulations do, however, provide a good overall estimation of the average process performance by giving the modeller a snapshot of the process which can be used for process evaluation and debottlenecking.

The first step is to draw the process layout in the graphical interface by dragging-and-dropping unit icons and connect the icons with appropriate streams. Units models can be classified into following categories: source blocks (stockpile), comminution (crusher and mills), classification (screens and splitters), combiner (hoppers and bins) and transport (conveyors). Source block defines the material properties, i.e. characterising the ore entering the process. These properties are related to the size distribution, flow rate, density, shape and strength of the material. This information is carried with the stream between the unit models throughout the process. In the comminution model, a transformation of the material occurs where the particle size distribution of the incoming flow (or flows) is reduced to a smaller particle size distribution which depends on the model's configuration. The classification and combiner models do not alter the material characteristics, however, as the name suggests separation 
and combination of streams happens. The separation of streams is based on the relative size between the particle size distribution and the classification media's opening. The transport units are applied for visualisation purposes within a steady-state simulation. No delay is included in steady-state simulation as that would only add computational time.

After the flowsheet of the process has been drawn the platforms performs a topological analysis to determine the computational sequence between the unit models to enable faster conversion of the mass and energy balance. The mass and energy balances are then achieved with a sequential-modular approach. Each sequence performs individual calculation for every unit model, which the model outputs depend on the identified input values, the model configuration, and the sequential order it is. The models receive input values from the pre-sequential unit either from a previous iteration or values from the current iteration depending on the relative sequential order between the units. This sequential approach is iterated until the equilibrium has been achieved. In other words, when the difference in mass and energy between each iteration within the streams are less the defined tolerance. Figure 1 shows an entire process sequence.

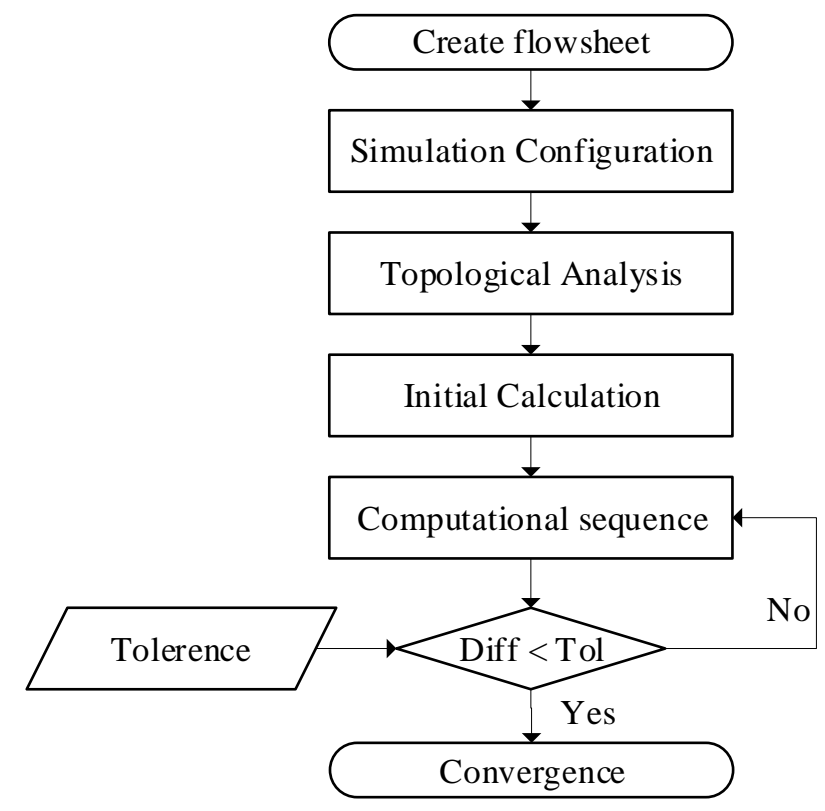

Figure 1. Algorithm for the sequence of calculations in Plantsmith.

\section{CASE STUDY DESCRIPTION}

Geita Gold Mine (GGM) is multiple open-pit and underground gold mines located in the northwestern region of Tanzania, in the Lake Victoria goldfields of Mwanza region. The mine is operated by Anglo Gold Ashanti (AGA) and processes 5.2 Mt. capacity of ore. The comminution process for the ore processing consists of a three-stage crushing plant followed by SAG-mill and Ball-mill circuit. The mine is expected to have a change in ore characteristics as the mining process is moving from open pit to underground. The tested new ore is changing in its grade, recovery, material properties (increased hardness).

In order to maintain the profitability and with the objective of cost reduction, the process is being investigated for a potential downsizing in the capacity as the ore grade is increasing compared to the existing ore grade. The current maximum throughput is nominally at $660 \mathrm{tph}$ while the circuit is expected to operate at 460 tph for the duration of the reduced throughput period (30\% capacity reduction). To operate at the low throughput level, a single-stage ball mill configuration derived from the current circuit was posited as a viable option. As a primary ball milling operation, the proposed circuit would require a finer crushed ore compared to the present feed supply that is specified for the existing SAG-Ball mill configuration. The study was conducted to assess the capability of the comminution circuit to operate at the proposed reduced throughput. Along with the reduced throughput, opportunities for process improvements on the existing circuit was also conducted. The primary objectives of the investigation were two-fold: 
- Coarse Comminution Circuit: To assess the capability of the crushing and screening circuit to deliver optimal feed to a single-stage ball mill circuit at the planned reduced throughput.

- Fine Comminution Circuit: To investigate the response of a single-stage ball mill circuit to a range of crushed feed size distributions simulated from the existing crushing and screening circuit at the planned reduced throughput.

The following paper presents the process and findings of different simulated concepts with their opportunities and pitfalls only for coarse comminution circuit. Figure 2 presents the existing layout of the coarse comminution circuit. The product of the coarse comminution circuit is expected to change from existing $0-40 \mathrm{~mm}$ size to $0-25 \mathrm{~mm}$ or $0-15 \mathrm{~mm}$. The company also posed multiple boundary conditions for the solution concepts such as avoid capital cost for new infrastructure and equipment, propose solutions with the use of existing process layout and equipment, and the maintenance schedule is disregarded. The study used steady-state simulation for analysis, while the work is limited in studying the dynamic process effects such as investigation for interlocks, bottleneck analysis and control systems.

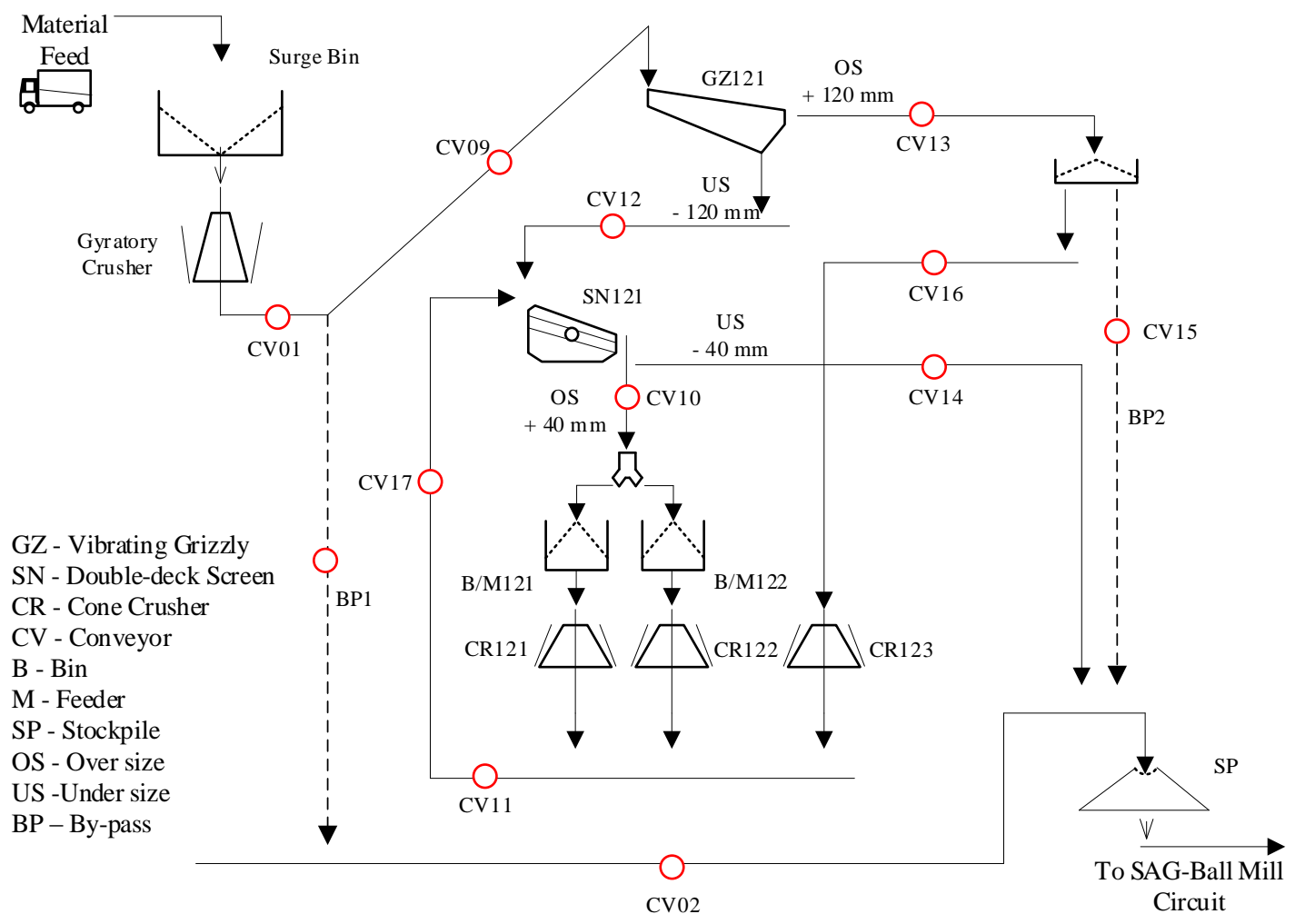

Figure 2. Plant layout of coarse comminution process at Geita Gold Mine.

\section{METHODOLOGY FOR PROCESS INVESTIGATION}

The general process of investigation used for the case study is presented in Figure 3. The first three stages in the process reflect the various possibility of capturing information and data from a physical process by observation, experimentation, laboratory test, and production data. Together, this forms a basis for simulation calibration and configuration. For the interest of the scope of this paper, the focus is on Stage 4 and Stage 5 where the simulation platform is used. 

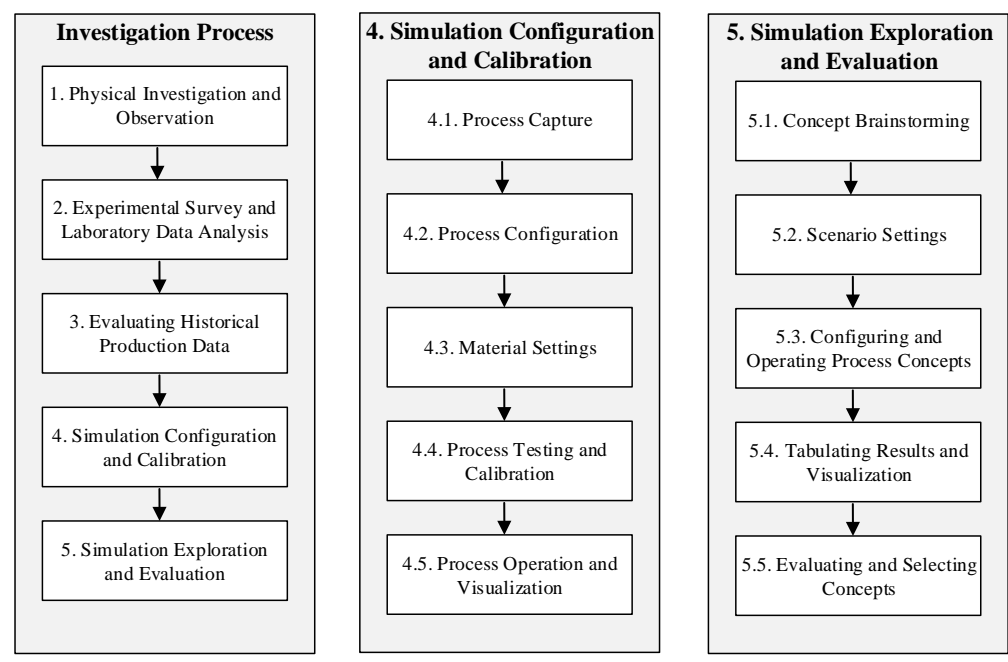

Figure 3. The investigation process and use of simulation for application in the operational comminution circuit.

\subsection{Simulation configuration and Calibration Process}

A brief step for simulation configuration and calibration using the experimental data collected from a user perspective for an existing plant is shown below.

- Process Capture: Draw the process layout in the simulation platform by selecting appropriate equipment model. It is important to select models that represent the equipment size and type present in the physical plant.

- Process Configuration: Individual equipment model settings are configured based on the survey data. A separate equipment model calibration can also be performed.

- Material Settings: The material feed properties from the source is configured. It is also possible to have target material setting on the product of the circuit or at the intermediate part of the circuit (for a de-coupled process).

- Process Testing and Calibration: Operate the plant at the steady-state mass flow values with similar assumptions as it was made during the survey testing and using the production data analysis results. Troubleshoot the basic errors in the simulation such as incorrect equipment setting, missing connections etc. Compare the mass flow and product size distribution (using reference P80 or P50) at the different measured point and corresponding simulated point.

- Process Operation and Visualization: Visually plot or tabulate the results between survey and simulation output. Obtain the results for different key performance indicators (KPIs).

\subsection{Simulation Exploration and Evaluation}

At this stage, a certain confidence level is reached in the process simulation to perform an exploratory study to evaluate multiple operating concepts of the crushing plant. Brief steps are illustrated below:

- Concept Brainstorming: Based on the need defined by the industrial partner and engineering design change possible within the circuit, a list of ideas is generated. For example, crusher can have operational setting change or chamber type change, or a completely new equipment change.

- Scenario Settings: The list of ideas can be further evaluated, categorised and grouped based on the technological, economic, and physical limits. The scenario settings help to organise concepts at different abstraction levels.

- Configuring and Operating Process Concepts: Each concept under different scenarios are configured and operated in the simulation platform. The concepts which violate the simulation possibilities (run-time errors) are eliminated and the successfully run concepts are carried forward.

- Tabulating Results and Visualization: The concepts simulated results and the corresponding key performance values are tabulated. Different visualization techniques can be used to present and compare the results.

- Evaluating and Selecting Concepts: The concepts are evaluated based on the industrial requirement and technological feasibility criteria. The concepts not complying to the 
requirements are rejected first to narrow down the choices. Usually, a set of plausible concepts are presented with their opportunities and pitfalls for the industrial partner to take decisions.

After this point, the detailed concept development, optimization, environmental assessment, economic evaluation, etc can be carried out.

The methodological process presented here is inspired by various engineering design early-stage product development process (Eppinger and Ulrich 2015) together with the knowledge within minerals processing (Napier-Munn et al. 1996; Asbjörnsson 2015; Bhadani 2019) and is adapted for continuous production process investigation. Investigating parallel concepts with elimination approach is inspired by the concurrent engineering approach (Wheelwright and Clark 1992).

\section{RESULTS: SIMULATION CONFIGURATION AND CALIBRATION}

Models of the major equipment were configured in Plantsmith using dimensions and process data (stream solids flow rates and size distributions) collected from trends and samples taken during the survey. The equipment models fitted include the grizzly screen, double deck vibratory screen; secondary and tertiary crusher models in Plantsmith. The simplified process configuration of the tested circuit is shown in Figure 4.

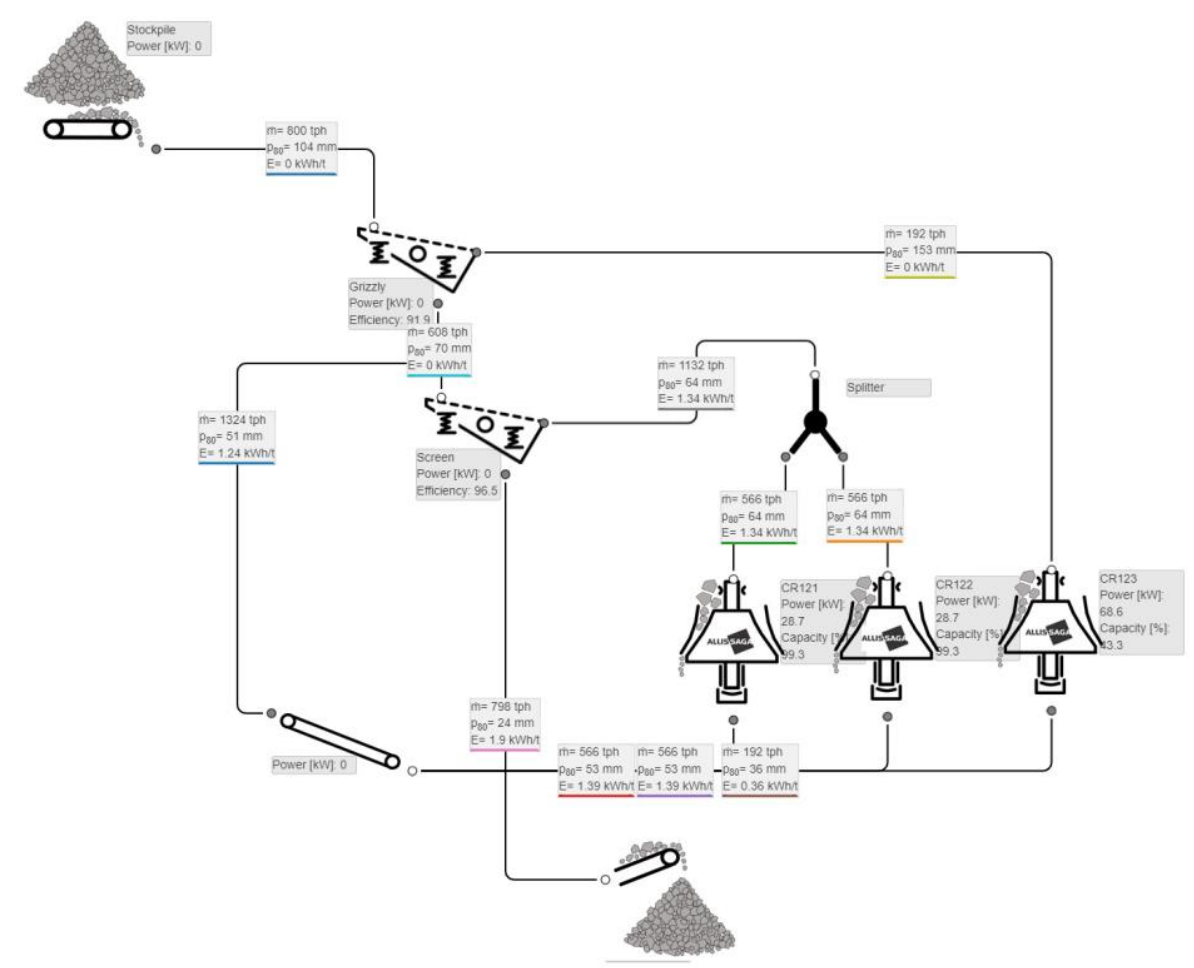

Figure 4. A configured process model of the circuit in Plantsmith.

The survey for mass balancing was carried out to push the plant to the maximum capacity, to run the crushers for maximum size reductions, and screen at the maximum loading condition. The basis for the survey crash stop was to operate the two tertiary crushers at their maximum capacity. Similarly, in the simulation, the two tertiary crushers were aimed to operate at $100 \%$ capacity, while the fresh feed rate from run-of-mine was adjusted. Since the process is highly dynamic and to configure the steadystate simulation model, the fresh feed rate to the plant was adjusted to represent the average operating scenario (based on production data analysis). Also, there is an accumulation of material in the bin which is not accounted in the calculations. Figure 5 shows the comparison between the product size distribution in survey data and model output. Table 1 shows the mass balance capacity in a steadystate model. 


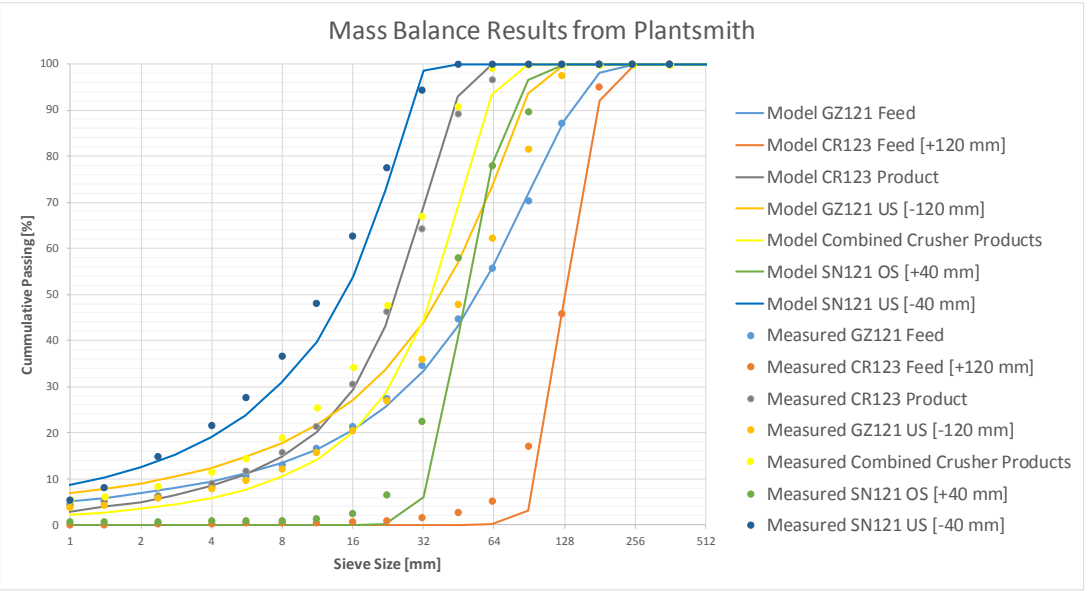

Figure 5. Product size distribution results from Plantsmith.

Table 1. Adjusted values for the mass balance capacity in a steady-state model.

\begin{tabular}{|l|l|l|l|l|l|}
\hline \multirow{2}{*}{ Stream } & \multicolumn{2}{|l|}{ Throughput [tph] } & \multicolumn{2}{l|}{} & \multicolumn{2}{l|}{ P80 [mm] } \\
\cline { 2 - 6 } & Measured & Model & Comment & Measured & Model \\
\hline GZ121 Feed & 1433 & 800 & $56 \%$ reduced & 110 & 104 \\
\hline CR123 Feed [+120 mm] & 329 & 192 & $58 \%$ reduced & 163 & 153 \\
\hline CR123 Product & 390 & 192 & x & 40 & 36 \\
\hline GZ121 US [-120 mm] & 1100 & 608 & $55 \%$ reduced & 87 & 70 \\
\hline CR121 Product & $\mathrm{x}$ & 566 & $\mathrm{x}$ & $\mathrm{x}$ & 53 \\
\hline CR122 Product & $\mathrm{x}$ & 566 & $\mathrm{x}$ & $\mathrm{x}$ & 53 \\
\hline Combined Crusher Products & 1335 & 1324 & Calibrated point & 39 & 51 \\
\hline SN121 OS [+40 mm] & 1039 & 1132 & Calibrated point & 67 & 64 \\
\hline SN121 US [-40 mm] & 991 & 798 & Calibrated point & 24 & 24 \\
\hline
\end{tabular}

\section{RESULTS: SIMULATION EXPLORATION AND EVALUATION}

For the downsizing project using single-stage ball mill configuration, it was decided to investigate the crushing circuit to produce products ranging from P80 of $12 \mathrm{~mm}$ to $24 \mathrm{~mm}$ which can generate different feed option to the milling circuit. Based on the various brainstormed ideas, three scenarios were set based on the economic significance of the engineering change as shown in Table 2. Scenario settings for concept generation. Each scenario consisted of five concepts based on the detailed abstraction level of operating parameter change as shown in Table 3. Just like the survey and configuration basis, in all the three scenarios, the tertiary crushers were aimed to operate at $100 \%$ capacity, while the fresh feed rate from run-of-mine was adjusted. Screen aperture was gradually reduced to obtain the target $\mathrm{P} 80$.

Table 2. Scenario settings for concept generation

\begin{tabular}{|l|l|l|l|}
\hline Entity & Scenario Setting 1 & Scenario Setting 2 & Scenario Setting 3 \\
\hline Change & Minor & Major & Intermediate \\
\hline Possible Cost & Low & High & Medium \\
\hline Feed Options & $\begin{array}{l}\text { Reference: Measured } \\
\text { from the survey }\end{array}$ & $\begin{array}{l}\text { Finer Feed: Blasting } \\
\text { technique change }\end{array}$ & $\begin{array}{l}\text { Reference: Measured } \\
\text { from the survey }\end{array}$ \\
\hline Primary Crusher & Reference & Reference & Reference \\
\hline Grizzly Aperture & Reference & Reduced from reference & Reduced from reference \\
\hline $\begin{array}{l}\text { Secondary } \\
\text { Crusher }\end{array}$ & Reference & $\begin{array}{l}\text { Chamber type change } \\
\text { Closed-side setting } \\
\text { change }\end{array}$ & $\begin{array}{l}\text { Chamber type change } \\
\text { Closed-side setting } \\
\text { change }\end{array}$ \\
\hline Tertiary Crusher & Reference & $\begin{array}{l}\text { Chamber type change } \\
\text { Closed-side setting } \\
\text { change }\end{array}$ & $\begin{array}{l}\text { Chamber type change } \\
\text { Closed-side setting } \\
\text { change }\end{array}$ \\
\hline Screen Aperture & Gradually reduced & Gradually reduced & Gradually reduced \\
\hline
\end{tabular}


Table 3. Concepts within each scenario and their operational settings.

\begin{tabular}{|c|c|c|c|c|c|c|c|c|c|}
\hline \multirow{2}{*}{$\begin{array}{l}\text { Scenario } \\
\text { Settings } \\
\end{array}$} & \multirow{2}{*}{$\begin{array}{l}\text { Fresh } \\
\text { Feed } \\
\text { Cap. } \\
\text { [tph] }\end{array}$} & \multirow{2}{*}{\begin{tabular}{|l|} 
Grizzly \\
Setting \\
Aperture \\
{$[\mathrm{mm}]$}
\end{tabular}} & \multicolumn{2}{|c|}{ CR121 Setting } & \multicolumn{2}{|c|}{ CR122 Setting } & \multicolumn{2}{|c|}{ CR123 Setting } & \multirow{2}{*}{$\begin{array}{l}\text { SN121 } \\
\text { Setting } \\
\text { Aperture } \\
{[\mathrm{mm}]}\end{array}$} \\
\hline & & & $\begin{array}{l}\text { Chamber } \\
\text { Type }\end{array}$ & $\begin{array}{l}\mathrm{CSS} \\
{[\mathrm{mm}]}\end{array}$ & $\begin{array}{l}\text { Chamber } \\
\text { Type }\end{array}$ & $\begin{array}{l}\mathrm{CSS} \\
{[\mathrm{mm}]}\end{array}$ & $\begin{array}{l}\text { Chamber } \\
\text { Type }\end{array}$ & $\begin{array}{l}\text { CSS } \\
{[\mathrm{mm}]}\end{array}$ & \\
\hline \multicolumn{10}{|l|}{ Set 1} \\
\hline GGM1 & 800 & 150 & EC & 35 & $\mathrm{EC}$ & 35 & EC & 23 & 44 \\
\hline GGM2 & 560 & 150 & $\mathrm{EC}$ & 35 & $\mathrm{EC}$ & 35 & EC & 23 & 37 \\
\hline GGM3 & 430 & 150 & EC & 35 & EC & 35 & EC & 23 & 30 \\
\hline GGM4 & 345 & 150 & EC & 35 & EC & 35 & EC & 23 & 25 \\
\hline GGM5 & 285 & 150 & EC & 35 & $\mathrm{EC}$ & 35 & EC & 23 & 20 \\
\hline \multicolumn{10}{|l|}{ Set 2} \\
\hline GGM6 & 1459 & 120 & $\mathrm{M}$ & 22 & $\mathrm{M}$ & 22 & $\mathrm{C}$ & 35 & 44 \\
\hline GGM7 & 1102 & 120 & $\mathrm{M}$ & 22 & $\mathrm{M}$ & 22 & $\mathrm{C}$ & 35 & 37 \\
\hline GGM8 & 782 & 120 & $\mathrm{M}$ & 22 & $\mathrm{M}$ & 22 & $\mathrm{C}$ & 35 & 28 \\
\hline GGM9 & 640 & 120 & $\mathrm{M}$ & 22 & $\mathrm{M}$ & 22 & $\mathrm{C}$ & 35 & 25 \\
\hline GGM10 & 543 & 120 & $\mathrm{M}$ & 22 & $\mathrm{M}$ & 22 & $\mathrm{C}$ & 35 & 22 \\
\hline \multicolumn{10}{|l|}{ Set 3} \\
\hline GGM11 & 1490 & 105 & $\mathrm{M}$ & 22 & $\mathrm{M}$ & 22 & $\mathrm{C}$ & 35 & 44 \\
\hline GGM12 & 1109 & 105 & $\mathrm{M}$ & 22 & $\mathrm{M}$ & 22 & $\mathrm{C}$ & 35 & 37 \\
\hline GGM13 & 779 & 105 & $\mathrm{M}$ & 22 & $\mathrm{M}$ & 22 & $\mathrm{C}$ & 35 & 28 \\
\hline GGM14 & 639 & 105 & M & 22 & $\mathrm{M}$ & 22 & $\mathrm{C}$ & 35 & 25 \\
\hline GGM15 & 537 & 105 & $\mathrm{M}$ & 22 & $\mathrm{M}$ & 22 & $\mathrm{C}$ & 35 & 22 \\
\hline
\end{tabular}

Example of the PSD feed generated from scenario 1 and 2 is shown in Figure 6. Similar feed was generated from scenario 3 as well.
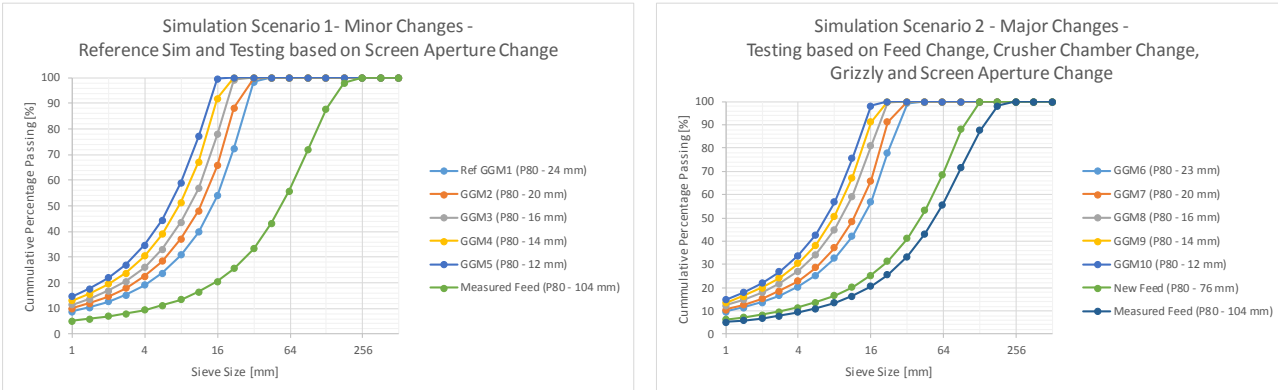

Figure 6. Simulated PSD feed for the milling circuit from crushing circuit.

A comparison between the capacity change of the circuit clearly shows that the changes in scenario 2 and 3 can meet the low P80 values requirements at a higher throughput rate, see Figure 7. The concepts GGM4 and GGM5 can be eliminated as it does not meet the new capacity requirements of the circuit.

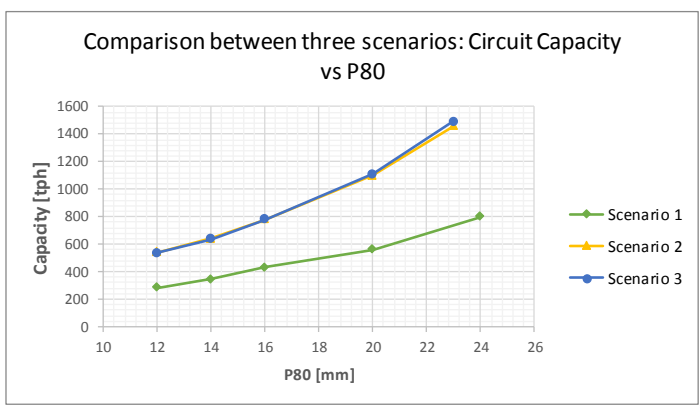

Figure 7. Capacity prediction of the circuit product with varying P80. 
Figure 8 shows the possibility of increased utilization of the secondary crushers which is higher in scenario 3 as affected by the change in grizzly aperture. At the same time, with the current configuration, the secondary crusher should not be utilized at $100 \%$ capacity because of the absence of the feeder bin (rejecting GGM11 and GGM12). Otherwise, it can lead to potential interlocks in the circuit.

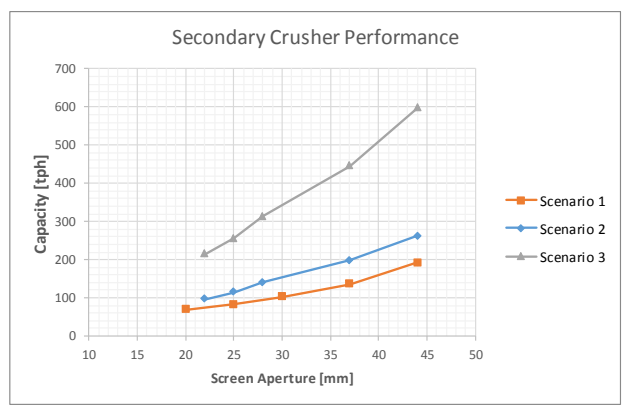

Figure 8. Capacity prediction of the secondary crusher.

As the circuit is intended to produce finer products, this will also lead to increased capacity utilization of the screens, see Figure 9. With the increased capacity and reduced aperture size, there is a potential of a drop in the screening efficiency. Caution needs to be taken to not overload the equipment (doubledeck screen), otherwise, it could lead to a bottleneck. The capacity performance and aperture of the existing screen need to be cross verified with the manufacturer's specifications.

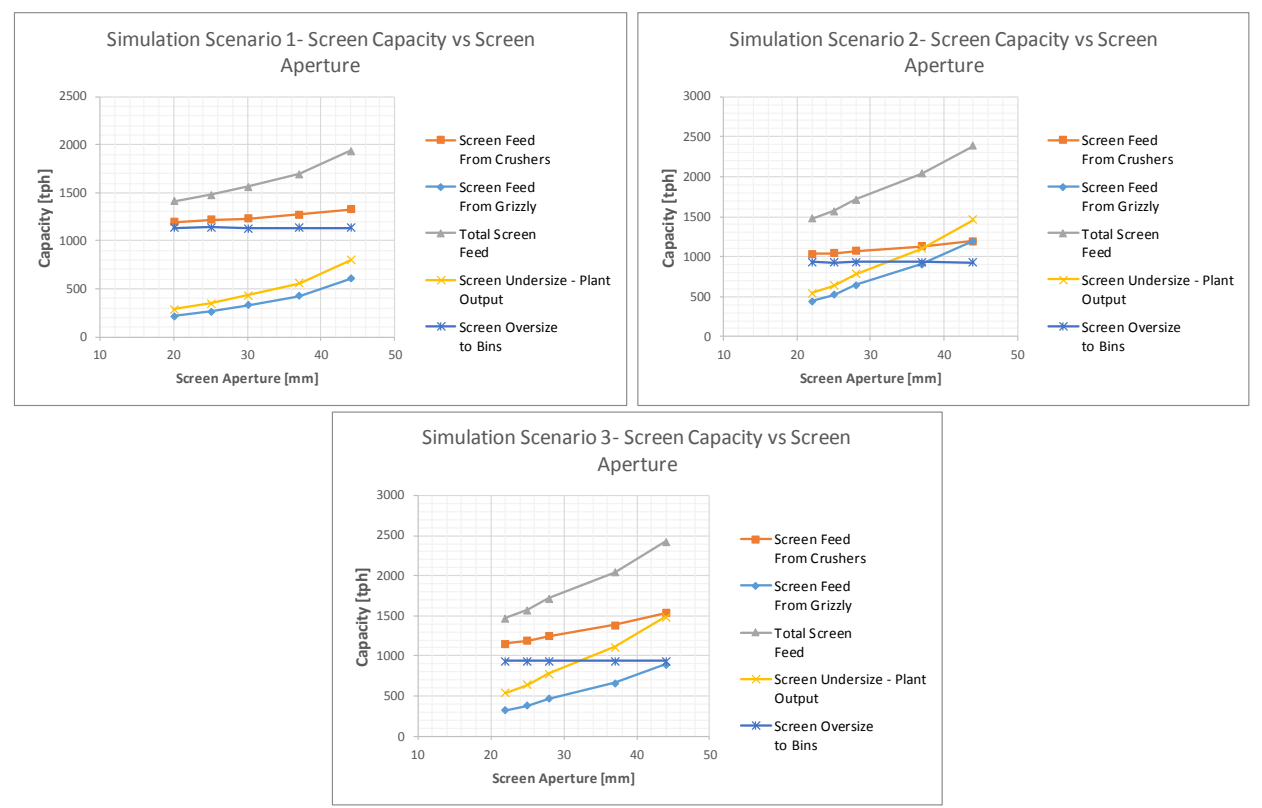

Figure 9. Capacity prediction of the double-deck screen.

Also, the other equipment such as conveyors needs to be reconfigured based on the capacity change to avoid the bottleneck. Fine-tuning in crusher settings such as CSS is not performed at this stage. The current process is also inherently unstable and the fluctuations on the configuration need to be further analysed to not risk a disturbance amplification when progressing to a smaller aperture in the screen. The product solution coarse comminution circuit still needs to be verified for feasibility in the fine comminution circuit (milling) before the final selection of concepts can happen.

\section{CONCLUSIONS}

In this paper, a systematic procedure is presented for performing an investigation of a coarse comminution circuit for improvements and modification. Testing of possible options (simulation exploration) for the downscaling capacity of the plant is presented using a simulation tool. Multiple conceptual solutions were conceived and evaluated using simulation platform and requirements. A well-calibrated simulation increases confidence in results, reduces the effort and resources needed in the evaluation, and helps to avoid basic pitfalls. 
A simulation platform is a powerful tool, but it needs a process organisation to systemically work for finding solutions to the problem. These methodological processes need to be integrated and provided as a feature from software platforms to support such an application. The process of working with the simulation tools also needs adjustment, for example, in the case of designing a completely new circuit, the data from real plants do not exist. This can potentially alter the order of steps in the method presented in this paper. This is a potential future work to investigate the methodological process for different use cases. Another essence of the methodology presented in the paper is to combine the product development processes into comminution process design and development application which can lead to developing a utility for process simulation platform. The principle methodology presented can be extrapolated to recycling circuit design and aggregates circuit design to find alternative concepts for the various process requirements. The practical considerations of the process design are dissimilar in different industries which need to be accounted for such implementation for process development. For example, the objective of the aggregate production is to produce a certain size fraction of material while the objective in the minerals processing comminution circuit is to maximize the fine material. Technology and process-specific requirements need to be captured for concepts generation and elimination phase.

\section{ACKNOWLEDGMENTS}

This work was performed under a collaborative project between Anglo Gold Ashanti and the Amira P9 project team funded directly by Geita Gold Mine, Tanzania. Support from the production facility at the Geita Gold Mine, their resources and personnel are highly acknowledged for facilitating the work. Special thanks to the Metallurgical, Engineering and Training personnel who participated in this project from the site. Support from Roctim AB and their personnel for providing the process simulator Plantsmith is gratefully acknowledged. This work has been performed within the Sustainable Production Initiative and the Production Area of Advance at Chalmers; this support is gratefully acknowledged.

\section{REFERENCES}

Asbjörnsson, G. (2015) Crushing Plant Dynamics, Published thesis (PhD Thesis), Chalmers University of Technology.

Bhadani, K. (2019) Optimization Framework for Crushing Plants, Published thesis (Licentiate of Engineering), Chalmers University of Technology.

Eppinger, S. and Ulrich, K. (2015) Product design and development, McGraw-Hill Higher Education.

Evertsson, C.M. (2000) Cone Crusher Performance, Published thesis (PhD Thesis), Chalmers University of Technology.

Karra, V.K. (1979) "Development of a model for predicting the screening performance of a vibrating screen", CIM bulletin, 72(804), 167-171.

King, R.P. (2001) Modeling and Simulation of Mineral Processing Systems, Elsevier Science.

Napier-Munn, T.J., Morrell, S., Morrison, R.D. and Kojovic, T. (1996) Mineral Comminution Circuits: Their Operation and Optimisation, Indooroopilly, Qld Australia: Julius Kruttschnitt Mineral Research Centre, The University of Queensland.

Roctim AB (2021) Plantsmith - Process Simulator, available: https://www.roctim-plantsmith.com/ [accessed 2021-01-12].

Soldinger, M. (2002) “Transport velocity of a crushed rock material bed on a screen”, Minerals Engineering, 15(1), 7-17. https://doi.org/10.1016/S0892-6875(01)00192-3

Wheelwright, S.C. and Clark, K.B. (1992) Revolutionizing product development: quantum leaps in speed, efficiency, and quality, Simon and Schuster.

Whiten, W.J. (1972) "The simulation of crushing plants with models developed using multiple spline regression", Journal of the Southern African Institute of Mining and Metallurgy, 72(10), 257-264.

Wills, B.A. and Napier-Munn, T. (2006) Wills' mineral processing technology: an introduction to the practical aspects of ore treatment and mineral recovery, Publisher: Butterworth-Heinemann, 12, 266-344. 